\title{
Role of Monetary and Fiscal Policies in Residential Investment: An Empirical Analysis of Japanese Data
}

\author{
Piyush TIWARI*
}

The relationship between macroeconomic activity and residential expenditure over1976: 1 to 2001: 1 has been examined in Japan. The analysis is conducted using variance decompositions (VDCs) and historical decompositions (HDs). The VDCs indicate that shocks to money stock, output and interest rates have significant impact on residential expenditure. The paper also compares the relative importance of various macroeconomic variables in determining residential investment using HDs of variance of residuals for the residential investment for three periods (pre bubble period, bubble period and post bubble period).

\section{INTRODUCTION}

Policy makers and academicians have long been interested in understanding the fluctuation evident in investment activity in the housing market. There are several reasons for this interest. First, the perceived value of residential fixed investment as a leading indicator has made understanding of this type of investment important. During recessions, residential expenditure led both real GNP and non-residential expenditure. Second, volatility in residential expenditure has an important impact on aggregate economic volatility. As shown in Fig. 1, residential expenditure has been much more volatile than GNP as a whole over the last four decades. Third, residential expenditure is generally sensitive to changes in interest rates and, thus is an important channel through which monetary policy changes can influence economic activity.

This paper is written with two objectives. The first is to analyze empirically the impact of macroeconomic activity on residential investment in the Japan over the period 1976: 1 to $2000: 1$. The second is to investigate the extent to which shocks to various macro aggregates are able to explain residential investment following the bubble period of early nineties. This paper analyzes the effects of various fiscal and monetary policies in the context of a small vector autoregressive (VAR) model, which includes monetary and fiscal measures, the price level, interest rates and output.

Seven variables are included in the analysis. Housing market activity is measured by real residential investment $(R E)$. Monetary and fiscal policy are represented by real M2 $(M)$ and real government expenditure $(G)$. $\mathrm{M}$ and $\mathrm{G}$ are included in the model because policy manipulations of $\mathrm{RE}$ potentially plays an important role in the manipulation of national output levels. Both long term $(R L)$ and short term $(R S)$ interest rates are considered-Bank of Japan short term lending rate

Institute of Policy and Planning Sciences

University of Tsukuba

Tsukuba $305-8573$

E-mail:tiwari@sk.tsukuba.ac.jp

${ }^{1}$ Based on Akaike Information criteria the number of lags chosen is 10.

${ }^{2}$ TSP 4.5 Software computes these values based on Osterwald (1992). 


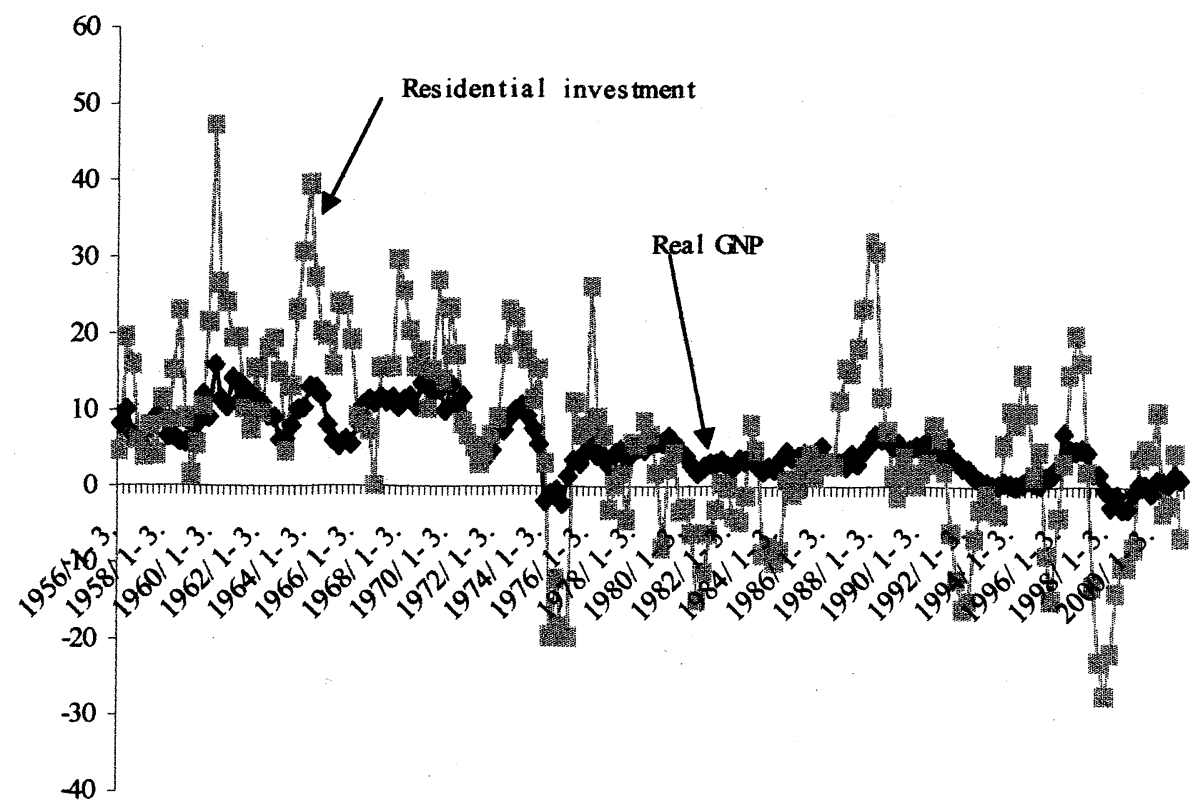

Figure 1: Real GNP and Residential Investment Growth

and long term prime lending rate, The long term interest rate $(R L)$ is presumably the relevant rate for investment decisions. However, open market operations are conducted with the short term instruments. Hence, monetary policy has influence on the short term interest rates $(R S)$ first. Changes in short term interest rates then lead to changes in long term rates via the term structure. Real GNP $(Y)$ and the GNP deflator $(P)$ are other variables in the system. $Y$ is included in the model because accelarator theories of investment argue that output is a major determinant of investment. $\mathrm{P}$ is included in the analysis because the cost of living presumably plays a role in the housing investment decision.

Section II discusses the methodology employed in the paper, while section III reports a preliminary data analysis. The impacts of macroeconomic activity on residential investment are discussed in section IV and section $\mathrm{V}$ concludes the discussion.

\section{METHODOLOGY}

Our analysis employs a VAR model to examine the impact on residential investment of a variety of macroeconomic influences. This VAR model is used to construct variance decompositions (VDCs) and historical decompositions (HDs). VDCs show the portion of variance in the prediction error of each variable in the system that is attributable to its own innovations and to shocks to other variables in the system. Both direct and indirect effects are captured by the VDCs. For example, if shocks to $M$ explain more of the variance in RE than do shocks to $G$, this indicates that $M$ has the larger influence on $R E$.

HDs are used much less frequently than VDCs, although both are based on the moving-average representation of the VAR model. Burbidge and Harrison (1986) point out that historical decomposition partitions the responsibility between what may be called base projection and the actual series among the innovations to the variables in the VAR. McMillion (1988, p. 326) notes, 'The extent to 
which the shocks to a particular variable or a particular set of variables close the gap between the base projection and the actual series is a measure of importance of that variable or that set of variables'.

The moving-average representation of the VAR can be written as

$$
Y_{t}=\sum_{i=0}^{\infty} Z_{i} U_{t-i}
$$

where $Y_{t}$ is a vector of endogenous variables, ut is a vector of serially uncorrelated disturbances with a diagonal covariance matrix and $Z_{i}$ is a matrix of impulse response weights conformable to $Y$ and $u$. Now consider a base period projection which runs from observation 1 to observation $T$. The value of $Y$ in periods after $T$ may be written as

$$
Y_{T+j}=\sum_{i=j}^{\infty} Z_{i} u_{T+j-i}+\sum_{i=0}^{j=1} Z_{i} u_{t+j-i}
$$

$\sum_{i=j}^{\infty} Z_{i} u_{T+j-i}$ is the base projection, or forecast of $Y_{T+j}$ based upon shocks on the system's variable up to time $T . \quad \sum_{i=0}^{j-1}$ is the part of $Y$ accounted for by shocks since time $T$. The elements of the second term are used to determine the extent to which shocks to a particular variable close the gap between $Y_{T+j}$ and the first term. The importance of a variable (or variables) is measured by the extent to which innovations (since $T$ ) in that variable (or variables) close the gap between the base projection and the actual series.

\section{PRELIMINARY DATA ANALYSIS}

Ohanian (1988), among others, cautions against interpreting VDCs in VARs estimated with potentially integrated regressors. Hence, empirical analysis is begun by examining the time series properties of the data. In particular, unit roots in the univariate representations of the variables and a cointegrating relationship among all the variables in the system are tested.

The covariance function of the stationary, variable $X_{t}$, Cov $\left(X_{t}, X_{t-i}\right)$ depends only on the lag $i$. If the variable needs to be differenced $\mathrm{k}$ times to be stationary, then the variable is said to have $k$ unit roots or be integrated of order $k$, i.e., $I(k)$. A stationary series is $I(O)$. The null hypothesis that an autoregression of each series contains a unit root against the alternative that it is stationary around the linear time trend is tested. The most common test for unit root is the so-called Augmented Dickey Fuller (Dickey et. al., 1981) test. However, this test is suitable only for seasonally adjusted data. However, when we use seasonally unadjusted series there are possibilities of seasonal roots also to exist. Hylleberg, Engle, Granger and Yoo (1990) developed a test referred hereafter as HEGY test, which checks for seasonal unit roots. The HEGY procedure consists of following regression:

$$
\Psi(L) \Delta_{4} x_{t}=\mu+\beta t+\Pi D_{t}+\Pi_{1} Y_{1, t-1}+\Pi_{2} Y_{2, t-1}+\Pi_{3} Y_{3, t-2}+\Pi_{4} Y_{3, t-1}+\epsilon_{t}
$$

where $\mu$ is a constant, $t$ is a time trend, $\Psi(L)$ is a polynomial autoregression correction term, $D_{t}$ are the deterministic seasonal dummies and $\Delta_{4} x_{t}=x_{t}-x_{t-4}$, that is, the fourth order difference of series $x_{t}$. The terms $Y_{1, t}$ to $Y_{3, t}$ reflect the fact that a fourth-order difference may be further decomposed as follows:

$$
\begin{gathered}
(1-L)\left(1+L+L^{2}+L^{3}\right) x_{t} \equiv(1-L) Y_{1, t} \\
(1-L)\left(1+L+L^{2}+L^{3}\right) x_{t} \equiv(1-L) Y_{2, t} \\
\quad\left(1-L^{2}\right)\left(1+L^{2}\right) x_{t} \equiv\left(1-L^{2}\right) Y_{3, t}
\end{gathered}
$$


Equation (4) to (6) define the existence of four possible unit roots in seasonally unadjusted data. Equation (4) represents that part of $x_{t}$ free of seasonal roots, while equation (5) and (6) suggests that a unit root can exist at the biannual and annual frequencies, respectively. In estimating equation (3), the unit root found in seasonally adjusted data signifies accepting the null that $\Pi_{1}$ is zero. A finding that $\Pi_{2}$ is zero implies existence of a unit root at the twice yearly seasonal cycle, while, if both $\Pi_{3}$ and $\Pi_{4}$ are zero, there is a unit root at the annual seasonal cycle. HEGY (1990) give critical values for this test.

Table 1 presents the results of the HEGY test. The optimum lag length of the change in the lag dependent variable is basad on Akaike and Schwarz information criteria.

The sample period runs from 1976: 1 to 2001: 1 . The series examined for unit roots are $G, M$, $Y, P, R E, R S$ and $R L$. All variables except RL and RS are represented in their logarithmic form. Results in Table 1 (Panel A) indicate that the null hypothesis of a unit root in the level of each variables is not rejected at the $5 \%$ level of significance. All series included in this study have unit roots. Except for $Y$ all other variables have seasonal unit roots.

Engle and Granger (1987) have pointed out that a VAR estimated with differenced data will be misspecified if the variables are cointegrated and the cointegrating relationship is ignored. A vector of variables is cointegrated if each element of the vector has a single unit root but a linear combination of the variable does not.

Consider a VAR model with $m$ variables, or

$$
Y_{t}=\sum_{j=1}^{k} A_{j} Y_{t-j}+u_{t}
$$

where for simplicity intercept term has been excluded. If all its $\mathrm{m}$ variables are integrated of order 1 , model can be rewritten as

$$
\Delta Y_{t}=B Y_{t-1}+\sum_{j=1}^{k-1} B_{j} \Delta Y_{t-j}+v_{t}
$$

where

$$
B=-\left(I-A_{1}-A_{2}-\cdots-A_{k}\right)
$$

and

$$
B_{j}=-\left(A_{j+1}-A_{j+2}-\cdots-A_{j+k}\right) \text { for } j=1,2, \cdots k .
$$

If all variables are integrated of order one then variables $\Delta Y_{t-j}$ are stationary. This model can be consistently estimated under the assumption that its variables are cointegrated, so $B Y_{t-1}$ is also stationary. Following Johansen (1989), if the rank of matrix $B$ is zero, variables are not cointegrated. If rank of $B$ is equal to $m$, then all variables are integrated of order zero and therefore the question of cointegration does not arise. If rank of matrix $B$ is $r$, where $r<m$, i.e., its rows are not linearly independent, it can be shown that this matrix can be written as

$$
B=D \cdot C^{\prime}
$$

where $D$ and $C$ are matrices of mxr dimensions. Matrix $C$ is called cointegration matrix and matrix $D$ is called the adjustment matrix. In the case where $Y_{t} \sim I$ (1) then $C^{\prime} Y_{t} \sim I$ (0), i.e., the variables in $Y_{t}$ are cointegrated. The rank of matrix defines the number of cointegrating vectors. Johansen (1988) provides a maximum likelihood procedure to identify the cointegrating rank, $r$. According to the trace test suggested by Johansen, finding the rank of cointegrating matrix is testing the hypothesis of presence of $r=0$ versus $r \geq 1$; hypothesis $r \leq 1$ versus $r \geq 2$ and so on. The 
Table 1 : Unit root and cointegration tests

\begin{tabular}{|c|c|c|c|c|c|c|}
\hline \multicolumn{7}{|c|}{ Panel A : HEGY statistics for seasonal unit-root tests } \\
\hline \multirow[t]{2}{*}{ Variables } & \multicolumn{5}{|c|}{ Frequency } & \multirow[t]{2}{*}{ Conclusion } \\
\hline & 0 & $1 / 2$ & $1 / 4$ & $1 / 4$ & $\begin{array}{l}\text { F-Test at } \\
\text { frequency } \\
1 / 4\end{array}$ & \\
\hline$G(\mathrm{O})$ & -1.92 & $-4.56^{*}$ & -1.23 & $-3.71^{*}$ & $-7.87^{*}$ & SI $(1,1)$ \\
\hline$M(\mathrm{O})$ & -0.55 & $-3.19 *$ & $-6.81^{*}$ & $-8.38^{*}$ & $162.75^{*}$ & SI (1.1) \\
\hline$Y(1)$ & -1.16 & -0.46 & -1.13 & $-1.84^{*}$ & $2.33^{*}$ & SI (1.0) \\
\hline$P(1)$ & -0.67 & $-3.40^{*}$ & -1.36 & $-1.13^{*}$ & $1.57^{*}$ & SI (1.1) \\
\hline$R S(0)$ & -3.43 & $-7.58^{*}$ & $-6.89^{*}$ & $-2.28^{*}$ & $30.14^{*}$ & SI (1.1) \\
\hline$R L(0)$ & -2.41 & $-6.11^{*}$ & $-5.97^{*}$ & $-4.86^{*}$ & $43.94^{*}$ & SI (1.1) \\
\hline$R E(0)$ & -1.35 & $-7.40^{*}$ & $-4.98^{*}$ & $-3.92^{*}$ & $25.78^{*}$ & SI (1.1) \\
\hline \multicolumn{7}{|c|}{ Panel B : Cointegration test ${ }^{1}$ (Johansen, 1989) } \\
\hline & & & \multicolumn{2}{|c|}{ Trace statistics } & \multicolumn{2}{|c|}{$p$-value ${ }^{2}$} \\
\hline $\mathrm{HO}: r=0$ & & & \multicolumn{2}{|c|}{134.43} & \multicolumn{2}{|c|}{0.01} \\
\hline $\mathrm{HO}: r<=1$ & & & \multicolumn{2}{|c|}{77.99} & \multicolumn{2}{|r|}{0.42} \\
\hline \multicolumn{3}{|l|}{ HO : $r<=2$} & \multicolumn{2}{|c|}{42.62} & \multicolumn{2}{|r|}{0.87} \\
\hline \multicolumn{3}{|l|}{$\mathrm{HO}: r<=3$} & \multicolumn{2}{|c|}{27.71} & \multicolumn{2}{|r|}{0.81} \\
\hline \multicolumn{3}{|l|}{$\mathrm{HO}: r<=4$} & \multicolumn{2}{|c|}{14.86} & \multicolumn{2}{|r|}{0.79} \\
\hline \multicolumn{3}{|l|}{$\mathrm{HO}: r<=5$} & \multicolumn{2}{|c|}{5.46} & \multicolumn{2}{|r|}{0.80} \\
\hline \multicolumn{2}{|l|}{$\mathrm{HO}: r<=6$} & & \multicolumn{2}{|c|}{0.83} & \multicolumn{2}{|r|}{0.71} \\
\hline
\end{tabular}

* Significant at $5 \%$ level

test stops where the likelihood ratio statistics computed by the test is less than critical value suggested by Johansen and Juselius (1990). The accepted null gives the rank, which is equal to number of cointegrating vectors.

Table 1, Panel B indicates that the null is rejected for $r=0$ and can not be rejected for $r \leq 1$ indicating the presence of one cointegrating vector. Because of relatively strong evidence of presence of a unit root in each of variables, and presence of a cointegrating relationship among the variables, the VAR model is estimated in levels.

\section{RESIDENTIAL INVESTMENT AND MACROECONOMIC ACTIVITY}

The main results of the paper are cointained in the VDCs and HDs. Because no contemporaneous terms enter the equations of a VAR, any contemporaneous relations among the variables are reflected in the correlation of residuals from the various VAR equations. In this paper, a Choleski decomposition is used to produce the orthogonal residuals necessary to compute VDCs and HDs. The Choleski decomposition requires that the variables in the VAR be ordered in a particular fashion. Because of the cross-equation residual correlation, when a variable higher in the ordering changes, all variables lower in the ordering are assumed to change. The extent of the change 
depends on the degree of the residual correlation. The orderings considered are (1) $G, M, Y, P$, $R S, R L, R E$ and (2) $G, M, P, Y, R S, R L, R E$.

These orderings reflect the primary focus of the paper. The policy variables are placed first in each ordering. This allows policy variables to affect the other variables in the system contemporaneously. Placement of $R E$ last in each ordering allows shocks to each of the other variables to alter $R E$ contemporaneously. This is consistent with past investment studies in which current values of the explanatory variables affect investment. $R S$ and $R L$ are placed after $G, M, Y$ and $P$ based on efficient markets arguments of Gordon and Veitch (1986). Term structure considerations place the short term interest rate $(R S)$ above the long term interest rate $(R L)$ in the orderings.

The VDC results are reported in Table 2. Given that the main focus of the study is the impact of macroeconomic variables on $R E$, only the decomposition of $R E$ is reported. An analysis of Table 2 indicates that shocks to $G$ explain a slightly larger portion of the variance in $R E$ than do shocks to $M$. Government has played a very active role in promoting residential investment through Government Housig Loan Corporation (GHLC) in Japan. GHLC provides subsidized credit for the purchase of housing by lower and middle income home buyers. The share of GHLC financed owner-occupied houses is around $49 \%$ of the total owner occupied houses financed. In the housing for sales category, the share of GHLC funded houses is 36.1\% (GHLC, 2000). The main source of funding for GHLC is treasury investment and loans from Postal savings, Postal Life Insurance, Pensions etc. Besides this some part of the fund is contributed from the general account of the Government.

Table 2 indicates that interest rate shocks explain significant portions of the variance in $R E$ at each time horizon. For longer time horizons, the two interest rates combined explain more than $25 \%$ of the variance in $R E$. $Y$ shocks also play an important role. In the first ordering, shocks to $Y$ explain over $10 \%$ of the variance in $R E$. In the second ordering, $Y$ explains over $10 \%$ of variance in the longer time horizon. This indicates that accelarator effects are an important determinant of RE. Shocks to $P$ explain a significant portion of the variance in $R E$ in both orderings and more pronounced in the second ordering. Cost of living has played an important role in determining the residential investment. This is also consistent with the neoclassical theories of investment where cost of capital plays an important role in investment decisions.

The period 1986: 1 to 1990: 4 is generally regarded as the bubble period in Japan. The land prices in Japan increased rapidly between 1986 and 1987. This was also the period of deregulation of Tokyo financial market and the income grew by more than $10 \%$. However, after 1991, the Japanese economy went into recession. The land prices fell sharply. To check the role of policies in determining residential investment, we compute HD for three periods between 1981: 1 to 1985 : 4 (20 quarters prior to bubble period), between 1986: 1 to 1990: 4 (20 quarters during the bubble period) and between 1991: 1 to 1995: 4 (20 quarters after the bubble period). A comparison of HDs during these three periods allow us to determine how the relative importance of shocks to $G, M, Y$, $P, R S$ and $R L$ changed between these three periods. It may be that shocks to a given variable help close the gap between the base projection of $\mathrm{RE}$ and the actual series in one period, but not in the other.

Policy changes, especially monetary policy changes, seldom involve a change in one variable only. A change in the money supply leads to changes all along the term structure. For this reason, improvement in forecasting $\mathrm{RE}$ is examined when shocks to both interest rates $(R S+R L)$ and shocks to $M$ plus shocks to both interest rates $(M+R S+R L)$ are added to the base projection. Adding $R S+R L$ shocks to the base projection shows the improvement in forecasting when shocks 
Tabe 2: Variance decomposition for $R E$

\begin{tabular}{|c|c|c|c|}
\hline \multirow{2}{*}{$\begin{array}{l}\text { Explained by } \\
\text { innovations in }\end{array}$} & \multirow[t]{2}{*}{ Horizon (Quarters) } & \multicolumn{2}{|c|}{ Relative variations in $R E$} \\
\hline & & Ordering 1 & Ordering 2 \\
\hline \multirow[t]{4}{*}{$G$} & 4 & 5.54 & 5.54 \\
\hline & 8 & 5.03 & 5.03 \\
\hline & 12 & 6.04 & 6.04 \\
\hline & 16 & 7.58 & 7.58 \\
\hline \multirow[t]{4}{*}{$M$} & 4 & 3.53 & 3.53 \\
\hline & 8 & 3.15 & 3.15 \\
\hline & 12 & 4.23 & 4.23 \\
\hline & 16 & 6.80 & 6.80 \\
\hline \multirow[t]{4}{*}{$Y$} & 4 & 16.22 & 6.20 \\
\hline & 8 & 13.51 & 8.97 \\
\hline & 12 & 11.56 & 10.30 \\
\hline & 16 & 11.12 & 11.77 \\
\hline \multirow[t]{4}{*}{$P$} & 4 & 10.68 & 20.70 \\
\hline & 8 & 7.64 & 12.18 \\
\hline & 12 & 8.92 & 10.18 \\
\hline & 16 & 10.16 & 9.51 \\
\hline \multirow[t]{4}{*}{$R S$} & 4 & 6.58 & 6.58 \\
\hline & 8 & 14.91 & 14.91 \\
\hline & 12 & 17.63 & 17.63 \\
\hline & 16 & 16.64 & 16.64 \\
\hline \multirow[t]{4}{*}{$R L$} & 4 & 4.56 & 4.56 \\
\hline & 8 & 11.26 & 11.26 \\
\hline & 12 & 12.68 & 12.68 \\
\hline & 16 & 12.40 & 12.40 \\
\hline \multirow[t]{4}{*}{$R E$} & 4 & 52.89 & 52.88 \\
\hline & 8 & 44.48 & 44.48 \\
\hline & 12 & 38.93 & 38.93 \\
\hline & 16 & 35.28 & 35.28 \\
\hline
\end{tabular}

from both interest rates are taken into account. Adding $M+R S+R L$ shocks to the base projection shows the improvement in forecasting when shocks to all monetary variables are taken into account.

In order to examine the contribution of a given variable (or variables) to closing the gap 
Table 3: Historical decomposition summary $(\mathrm{MSE} \times 10-2)$

\begin{tabular}{|c|c|c|c|}
\hline & $\begin{array}{l}\text { MSE } \\
1981: 1 \text { to } 1985: 4\end{array}$ & $\begin{array}{l}\text { MSE } \\
1986: 1 \text { to } 1990: 4\end{array}$ & $\begin{array}{l}\text { MSE } \\
1991: 1 \text { to } 1995: 4\end{array}$ \\
\hline$B P$ of $R E$ & 1.41 & 1.52 & 0.22 \\
\hline$B P+G$ & 1.20 & 1.87 & 0.23 \\
\hline$B P+M$ & 1.35 & 1.47 & 0.21 \\
\hline$B P+Y$ & 1.55 & 0.91 & 0.24 \\
\hline$B P+P$ & 0.96 & 1.9 & 0.28 \\
\hline$B P+R S$ & 0.96 & 0.85 & 0.20 \\
\hline$B P+R L$ & 0.69 & 0.68 & 0.18 \\
\hline$B P+R S+R L$ & 0.60 & 0.61 & 0.16 \\
\hline$B P+R S+R L+M$ & 0.62 & 0.63 & 0.14 \\
\hline
\end{tabular}

between actual $\mathrm{RE}$ and the base projection of $\mathrm{RE}$, a series of mean square errors (MSEs) have been computed. MSEs are constructed for the base projection versus actual RE and for the base projection plus the impact of shocks to a given variable (or variables) versus actual RE. The greater the reduction in MSE when shocks to a given variable(s) are added to the base projection, the more important are the variable(s).

The HDs are reported in Table 3. In the 1981: 1 to $1985: 4$ period, all variables except $Y$ produces an improvement in the forecasting of $R E . \quad M$, stand alone, produces smaller improvement compared to G. $R S$ and $R L$ combined improve the forecasting error significantly. This is particularly important for the first two periods because during this period the interest rates on housing loan have declined significantly. GHLC was also offering home loans which were below market rates. This indicates that in the first period both fiscal policy and monetary policy (as reflected in interest rates) were driving the residential expenditure. When $Y$ is added to the base projection it does not improve the MSE of the forecast. This indicates that income did not play any role during this period. In the next periods 1986: 1 to 1990: 4 (the bubble period), the MSEs indicate that $Y$ has become an important variable. Addition of this variable to base improves the forecast (shown by reduction in MSE). During the bubble period, income grew substantially and this was the driving force behind the residential investment. Monetary variables $(M, R S, R L)$ were still important factors. Price $(P)$ were not important during this period as it was one of the high inflation period in Japan. Fiscal policies $(G)$ also did not play any role. After the bubble (that is during 1991: 1 to $1995: 4$ ), the only variables determining residential investment are the monetary policy variables $(M, R S, R L) . G, Y$ and $P$ have not played any role in determining residential investment.

\section{CONCLUSION}

In this study the relationship between macroeconomic activity and residential investment over the period 1976: 1 to 2001: 1 has been examined. The analysis was conducted using variance decompositions (VDCs) and historical decompositions (HDs) derived from a vector autoregressive (VAR) model.

The VDCs indicate that government spending has had much larger effect than the money 
supply. That is, shocks to fiscal policies explain a larger portion of the forecast error variance in residential investment than shocks to money supply. Monetary variables together (money supply, short term and long term interest rates) explain around $35 \%$ of the forecast error variance. Comparatively, monetary policy variables have been more effective than fiscal policy variables in determining residential investment in Japan. Shocks to real output and price levels also explain significant portions of the variance in the prediction of residential expenditure.

The HDs have important policy implications. The HDs for the period 1981: 1 to $1985: 4$ indicate that the combined effect of shocks to monetary variables are helpful in forecasting residential expenditure. That is, adding RS and RL to the base projection produces significantly lower MSE than the MSE derived from the base projection alone. This behaviour has remained more or less same during the second period considered. In the third period, money supply also plays an important role besides RS and RL in determining residential expenditure. The importance of other variables has changed. Government spending, played a role before the bubble period (before $1986: 1$ ) but later does not explain variance in the prediction of residential investment. During the bubble period (1986: 1 to $1990: 4$ ), income was an important determinant of residential investment. After bubble, shocks to this variable do not improve the prediction of residential investment.

\section{References}

Burbidge, J. and Harrison, A. (1985) A historical decomposition of the great depression to determine the role of money, Journal of Monetary Economics, 14, 45-54.

Dickey, D.A. and Fuller, W.A. (1981) Likelihood ration statistics for autoregressive time series with a unit root, Econometrica, 49, 1057-72.

Engle, R.F. and Granger, C.W.J. (1987) Co-integration and error correction : representation, estimation and testing, Econometrica, 55, 251-76.

Engle, R.F. and Yoo, B.S. (1987) Forecasting and testing in co-integrated systems, Journal of Econometrics, 35, 143-59.

GHLC (2000) Housing and the Government Housing Loan Corporation, GHLC, Tokyo.

Gordon, R.J. (1986) Fixed investment in the American business cycle. 1919-83, In The American Business Cycle, Gordon, R.J. and Veitch, J.M. (Ed), pp. 267-357, The University of Chicago Press, Chicago, IL.

Hylleberg, S., Engle, R.F., Granger, C.W.J., Yoo, S. (1990), “Seasonal Integration and Cointegration”, Journal of Econometrics, Vol. 44, No. 1-2, pp. 215-238.

Johansen, S. (1988), "Statistical Analysis of Cointegration Vector", Journal of Economic Dynamics and Control, Vol. 12, pp. 213-254.

Johansen, S. and Juselius, K. (1990), "Maximum Likelihood Estimation of Nonlinear Simultaneous Equations with Additive Disturbances", Oxford Bulletin of Economics and Statistics, Vol. 52, pp. $169-210$.

Osterwald_Lenum, M. (1992), "Practitioners' Corner : A note with quantiles for the asymptotic Distribution of the maximum likelihood cointegration rank test statistic", Oxford Bulletin of Economics and Statistics, pp. 461-471.

Sims, C.A. (1985-86) Some subjective bayesian considerations in the selection of models: comment, Econometric Reviews, 4, 269-75. 